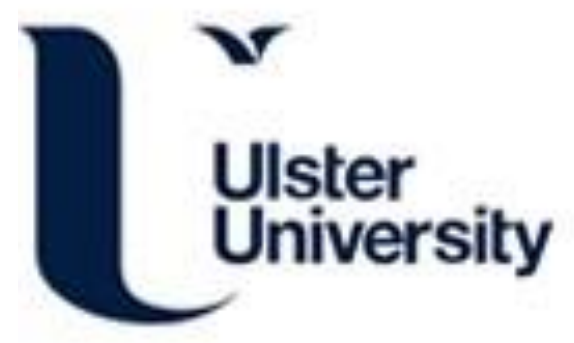

\title{
Living Labs: Frameworks and Engagement
}

Mulvenna, M., \& Martin, S. (2013). Living Labs: Frameworks and Engagement. In R. J. Howlett, B. Gabrys, K. Musial-Gabrys, \& J. Roach (Eds.), Innovation through Knowledge Transfer (pp. 135-143). Springer. https://doi.org/10.1007/978-3-642-34219-6_15

Link to publication record in Ulster University Research Portal

\section{Published in:}

Innovation through Knowledge Transfer

Publication Status:

Published (in print/issue): 01/01/2013

DOI:

10.1007/978-3-642-34219-6_15

\section{Document Version}

Publisher's PDF, also known as Version of record

\section{General rights}

Copyright for the publications made accessible via Ulster University's Research Portal is retained by the author(s) and / or other copyright owners and it is a condition of accessing these publications that users recognise and abide by the legal requirements associated with these rights.

\section{Take down policy}

The Research Portal is Ulster University's institutional repository that provides access to Ulster's research outputs. Every effort has been made to ensure that content in the Research Portal does not infringe any person's rights, or applicable UK laws. If you discover content in the Research Portal that you believe breaches copyright or violates any law, please contact pure-support@ulster.ac.uk. 


\title{
Living Labs: Frameworks and Engagement
}

\author{
Maurice Mulvenna, Suzanne Martin \\ TRAIL Living Lab, University of Ulster, Northern Ireland, UK
}

\begin{abstract}
This paper introduces the concept of living labs and shows the results of a survey of the living labs network. The main value of the study is that it provides findings about the diversity of living labs, how they engage with users and how strong the relationships are between living labs.
\end{abstract}

\section{Introduction}

The architect and academic, William J. Mitchell, created the concept of living labs. Mitchell, based at MIT, was interested in how city dwellers could be involved more actively in urban planning and city design (Mitchell, 2003). The ideas of citizen involvement in the design process was subsequently taken up and developed further in Europe by various research communities. A small number of living labs, created across Europe in 2005, primarily from the Computer Supported Cooperative Working (CSCW) research community, formed the European Network of Living Labs (ENOLL) in 2006. Successive waves of new living labs have since been created and, in 2011, there are, for example, 15 living labs in the UK and over 250 living labs across Europe and beyond.

This paper describes the results of a major survey of living labs, undertaken in 2011 (Mulvenna et al. 2011). This is the first major survey of the living labs themselves and the findings outline how living labs perceive themselves in terms of, for example, engagement with users, focus of work, future needs and financial position.

\section{Living Labs}

The ENOLL living labs recognise, as did Mitchell, that technology, in particular ICT plays a powerful catalytic role in user engagement and most of them are focused on using technology to support user engagement, research novel ways of engaging with users, and communicate findings rapidly and accurately using lowcost, mass-adopted tools such as social networks.

It is apparent from an examination of the living labs that many have a particular niche in which they operate. Some labs are region-based, others focus 
on a particular product family for example, automotive design, while others seek to address particular societal needs in, for example, healthcare. However, the use of technology to engage and support users as early as possible in product and service development is the common denominator for all of them.

\section{Survey method}

The survey was designed to establish basic information about the living lab phenomenon, which was 'born in the USA' but developed in Europe and beyond under the aegis of the European Network of Living Labs (ENoLL). As of October 2011, when the survey was completed, there were 274 living labs in existence. The survey was launched on 20 June 2011 and sent via email message to the contact details of 195 living labs, drawn from those extant 212 living labs from the first four waves where contact details could be ascertained and verified. The survey response rate was $28.7 \%$.

\section{Survey results}

The survey explored different topics including domains of activity of living labs and aspects relating to territory of the labs, before examining the users of the labs. The models used by living labs to engage with users were questioned, relating to techniques for engagement. The translation of results from engagement with users was the next focus of the survey, before how living labs are evaluated was considered. The 'user experience' in living labs was then surveyed before respondents were asked about the area of stakeholders in living labs and how living labs could be designed to be sustainable in the longer term. Finally, questions relating to how living labs interact with other living labs were asked before final questions exploring the financial models used for sustainability was surveyed.

\section{Domains of activity}

The initial question asked the labs to say which area or domain best describes the activity of their living lab. The responses were based upon the classification used by ENoLL, encompassing Digital Cities, E-Manufacturing, Energy Efficiency (aka Smart Energy Systems), E-Participation, Future Media and Content Delivery, Health and Wellbeing, and Tourism. It was interesting to note that 'other' was the response with the highest value. This may indicate that the classifications used in ENoLL are not representative of the domains in which the living labs practice, 
apart from the domain of 'Health and Wellbeing' selected by over a quarter of respondents. However, respondents had to choose a single domain to describe their activity and perhaps those living labs that operate across several domains selected 'Other' instead of picking the most representative domain in which they work.

\section{Territory}

The architect and academic, William J. Mitchell, created the concept of living labs. Mitchell, based at MIT, was interested in how city dwellers could be involved more actively in urban planning and city design. The ideas of citizen involvement in the design process was subsequently taken up and developed further in Europe by various research communities, primarily ENOLL.

When asked if the activity of their living lab was specific to their region, their country or was international in scope, a clear majority selected 'Regional' (58.9\%), while $33.9 \%$ selected 'International' and only $7.1 \%$ chose 'National'.

The responses to this question revealed what was believed only anecdotally beforehand, which was that living labs primarily operate at a regional level. This may be related to their genesis at a regional level, often within academic and research organisations, which will be examined in subsequent sections in this report.

Only a relatively small number selected 'National', indicating perhaps the minimal role in the development of living labs by national governments in Europe and beyond.

The European Commission provide implicit support to living labs by, for example, facilitating many living lab activities at practical as well as policy levels. The Commission also provide tangible explicit support, primarily in, for example, the incorporation of living lab methods and techniques in RDI calls for funding. This support by the Commission may be the reason for just over a third of the living labs indicating that they operate at 'International' level (33.9\%), where international perhaps translates as 'transnational activities' between European organisations who have already formed partnerships through RDI funded activities.

\section{Membership \& status}

The living labs were asked about the legal status of their lab. It was anticipated that academic and research organisations may host many living labs and that this would be reflected in the answer to this question. While $28.6 \%$ gave 'University' as a response, $30.4 \%$ of respondents indicated that the public sector hosted their living lab, breaking down as 'Government' $(10.7 \%)$ and 'Other Public Sector Organisation' (19.6\%). The unexpected response was that $16.1 \%$ of living labs have a legal status as 'Private Sector Organisations'. 
The majority of those who gave 'Other' $(25 \%)$ as an answer for the legal status of their lab were labs formed as public-private-academic partnerships, under the triple-helix model outlined in the introductory section of this article.

\section{Users - their engagement and involvement}

When asked approximately how many end users were involved in their living lab, there was a broad range of responses. Twenty-three living labs indicated that they involved 1-100 users (41.1\%), while fifteen indicated the involvement of 1011,000 users $(26.8 \%)$ and eighteen indicated over 1,000 users involved in their labs $(32.1 \%)$. One respondent indicated that they involved 1.4 million users, which may be feasible in this age of research using social media, but such figures should be treated with caution.

The next question put to the survey respondents asked how easy or difficult it had been to engage with end users, and 55.3\% answered that it was easy or very easy while $44.7 \%$ answered that it was difficult or very difficult.

\section{Indicators for impact}

In order to gain some insight about the indicators used by the living labs, the respondents were asked which indicators were used to measure the impact of their living lab. Many respondents (23\%) said that they were not currently using any indicators, primarily because their lab had not yet set these up.

Several labs responses included business like comments such as: "Profit", "commercial success, number of ideas, industry involvement", "returning customer, confirmed subscriptions to our partnership, revenue increase to customers, feedback collected through word of mouth", and in one case it was clear that the indicators of project funding organisations were being used "Will be subject to ERDF rules - jobs/SMEs supported" and "number and amount of external funding". Several responses related to intellectual property indicators, including: "Number of spin-outs, patents, products"; however, it was revealing that such indicators were cited by a small number (less than $4 \%$ ) of respondents.

Many labs cited more academic measures of performance including: "number of master theses, number of papers...", and a large number also cited general measures from academia, business and society, for example: "research output of the postgraduate researchers involved; - buy in and interest level of the community to the initiative; - interest of surrounding communities, government, and industry in our work".

However, the most common indicator cited by the respondents related to the engagement with end users: "Number of cases, number of end users, number 
of Living Lab projects", "Number of tests performed, Number of external customers, Number of end-users engaged", "The number of projects, and the number of users involved", "user satisfaction",

\section{Translating results}

In order to understand more about the processes involved in engaging with users, the respondents were asked how easy or difficult they found it to translate results or feedback from end users into actual service or product change.

A clear majority of living labs $(60.7 \%)$ answered that the translation process from end users to products or service change was difficult or very difficult, while $39.3 \%$ said that it was easy or very easy. While the response was expected in that a majority found it difficult or very difficult; it could be considered surprising that as high a percentage as $40 \%$ said that it was easy or very easy to carry out this fundamental process.

It was interesting to note that some respondents found that the reason was a kind of 'lost in translation' effect, for example: "it can be hard to get constructive and instructive comments from users that are not used to giving feedback and analysing a service working with small numbers in focus groups gives rich data but what if those statements are not reflected by the survey majority technical developers have own ideas and feasibility of request might not be given within a project timeframe and budget", "End user and engineers are not talking the same 'language' i.e., it is not always easy to understand what end user means and vice versa", "there is a need of translation, the language used is different when discussing with an expert or a layman", "Translation from end user to specialists" and "End users and developers are not speaking the "same language".

It is interesting to note that some living labs tackled the "lost in translation' effect mentioned above by tackling it head-on, for example: "By involving the developers in the user-activities it is more easy to transfer the user feedback", "If the feedback is captured in a structured manner then there is usually a clear way how to translate it into service/product improvement", "Because the users and the designers are the same group", "...because we gather users' feedback in a way that allows us to modify the service easily taking in mind this opinion. We try to guide the feedback sessions in a practical way", "We are currently doing research on this translation phase. When the analysis of user feedback is done collaboratively, it is not that difficult" and "Once they get to involve in the project it's more easy to get the results and the feedback". 


\section{Evaluating living labs}

The survey then asked several questions examining if living labs found it useful to have access to practical advice and assistance in several areas. On average, around three-quarters of respondents answered that they would find it useful to have access to advice and assistance in a variety of areas including 'Getting users interested', 'Getting end users involved in a practical way', 'Communicating the concept to end users', 'Getting end users to see the benefits' and 'Involving all end users rather than specific groups'.

Respondents were then asked about evaluation processes or procedures employed to learn how users view their experience of being involved in their living lab. In total, $73.2 \%$ of respondents answered that they did have some form of evaluation process in place, ranging from surveys to meetings or including both formal and informal processes, while $26.8 \%$ had no processes in place. This was perhaps a surprising result in that, more than other entities, living labs would be expected to ask their users about the experience given that the philosophy of living labs is all about engagement and evaluation.

For those respondents who did ask for feedback from users, the users' feedback was overwhelmingly positive or very positive $(91.1 \%)$ with only $1.8 \%$ giving negative feedback.

The living labs were then asked if they would find it useful to have access to evaluation and research training to assist with evaluating user involvement. $58.9 \%$ answered that they would find it useful to access evaluation and research training to assist with evaluating user involvement and only $17.9 \%$ said that they didn't need access to such resources. So, while (from earlier) $73.2 \%$ of respondents answered that they did have some kind of formal or informal evaluation process in place, a majority still would like access to support for evaluation and research training to assist with evaluating user involvement. This indicates that living lab respondents perhaps would benefit from techniques such as peer benchmarking with other living labs or access to training resources in order to understand better the practical aspects of evaluation of users.

\section{Stakeholders}

The survey then asked if organisations including government, other public sector organisations (e.g. Local Council), universities, private sector organisations and the European Commission were involved in the delivery of their living lab. This question partly relates to the earlier question asking about the legal status of the living labs where around two-thirds answered that their living lab was governed by a public sector organisation of some kind, but the primary purpose for asking 
respondents this question was to learn about the degree of penetration of triplehelix partnerships in the stakeholder mix for living labs operational activities.

The responses indicate that universities $(78.6 \%)$ and private sector organisations (75\%) are well embedded in the activities of living labs. The high value for 'Other public sector organisations' (71.4\%) and the low value for 'Government' $(44.6 \%)$ reflects the answers given earlier in relation to the question on the territorial specificity of the living labs, where almost two-thirds of living labs answered that they operated at a regional level while only $7.1 \%$ operated at a national level- perhaps more evidence that living labs are a phenomenon that operate more at a regional level, often with local councils. The significant impact by the European Commission (24\%) in this question's responses indicates that the living labs are to some extent 'children of the commission', for reasons discussed earlier, where the European Commission continues to support 'transnational activities' between European organisations who have already formed partnerships through R\&D\&I activities.

The living labs were then asked to say, for their region, how committed they would say organisations including 'Government, Other Public Sector Organisations, Universities, Private Sector Organisations, European Commission and Charities within their area' were to the concept of living labs. It was interesting to note that $33.9 \%$ of respondents reported Universities highest as 'Very committed' with the European Commission scoring second with 26.8\%. About half of respondents said that most organisations were 'Somewhat committed'.

In a closely related question, the respondents were asked if their living lab had found it easy or difficult to develop relationships with 'Government, Other Public Sector Organisations, Universities, Private Sector Organisations and European Commission'. It was interesting, albeit perhaps not so unexpected, that $23.2 \%$ of respondents answered that they had not tried to develop relationships with government. This response reinforces the analysis that living labs are a regional phenomenon and many national governments (there are exceptions) are quite disconnected from living labs and do not have well-developed policy frameworks relating to living labs, or indeed, arguably more broadly to support user or citizen participation.

A significant minority of respondents, ranging from a quarter to a third, said it was difficult to develop relationships across all the organisations. However, a clear majority answered that across all organisations, they found it easy to develop relationships. This confirms that living labs generally have relationships across the triple-helix mix of organisations and have found it easy to develop these relationships. 


\section{Sustainability}

The survey asked respondents how sustainable they considered their living lab to be. A clear majority of respondents $(78.6 \%)$ believed their living lab to be sustainable in the short-term of 1-2 years. Over a medium time horizon of 2-5 years, this percentage fell to $57.1 \%$. The fall can be attributed to growing uncertainty over time as the percentage of those who didn't know how sustainable their living lab would be over $2-5$ years rose to $28.6 \%$ (from $5.4 \%$ not knowing about sustainability in the short term of 1-2 years). Over the longer-term period of 5 years, most people simply didn't know how sustainable their lab would be $(76.8 \%)$. This increase in uncertainty over longer time periods may reflect the relatively precarious position of living labs, that while many are 'children of the Commission', their position is not underpinned by national legislation, their governance is a partnership of different interests and they are often regional actors with a regional remit and outlook.

The survey then asked the living labs what they believed were their top three challenges in the year to come. Many living labs provided the same three challenges but in all possible variations. These top challenges were, in descending order of priority: 1) funding; 2) getting more partners and end users (e.g., 'Get more external customers outside the region'); and 3) expanding activities and embedding user-centric activities in partners (e.g., 'Grow - to be able to manage more project in parallel').

\section{Relating to other living labs}

In terms of their relationships with other living labs, respondents were asked with how many other living labs their living lab had connections. Just over half of respondents $(51.8 \%)$ said that they had connections with four or more living labs with $26.8 \%$ saying that they had links with 1-3 living labs. The general degree of connectedness of living labs must be welcomed. However, It was revealing that $19.6 \%$ said that they had no connections with other living labs. On examination of the data, this group of living labs cited 'communication' as a challenge over the next year, and one of the living labs that had no connections with other living labs said that they worked with over 100,000 users.

In terms of how often living labs are in contact with other living labs, the responses indicate that the most common frequency is quarterly $(43.2 \%)$ with the remainder split between less frequently than that $(20.5 \%)$ and more frequently with $29.5 \%$ saying at least monthly and $6.8 \%$ saying at least weekly.

Those living labs that had four or more connections with other living labs had generally more frequent contact with those living labs, indicating that membership 
of a network brought with it more frequent interactions as a matter of course, perhaps related to the common 'network effect'.

\section{Financial support}

The survey asked the respondents if access to funding had been a problem for their living lab and $83.9 \%$ said that it was a problem, with $25 \%$ saying it was a minor problem and $58.9 \%$ saying that it was a major problem. The reason for the uncertainty in the longer time horizon of 3-5 years and beyond 5 years evident in the responses earlier is perhaps now revealed to be access to funding and therefore the key issue in the future for living labs will relate to sustainability.

The living labs were asked a final question about their main sources of funding. The public sector accounted for $42.9 \%$ of funding sources, breaking down to $25 \%$ for government and $17.9 \%$ for other public sector organisations. Universities accounted for $14.3 \%$ of funding with private organisations contributing $10.7 \%$. The European Commission accounted for $19.6 \%$ of funding, perhaps representing the support inherent in R\&D\&I activities from the instruments in the Framework 7 Programme (FP7) and the Competitiveness \& Innovation Programme (CIP).

\section{Discussion}

Most living labs provided support for product and/or service development, primarily related to using new technologies. While living labs began as an urban phenomenon, almost two-thirds of living labs are now 'territorial', that is, they primarily operate at a regional level. Responses indicate that universities and private sector organisations are well embedded in the activities of living labs and it was interesting to note that a third of respondents reported universities being very committed to their living lab with the European Commission scoring second with a quarter. It was also interesting, albeit perhaps not so unexpected, that a quarter of respondents answered that they had not tried to develop relationships with national government. This response supports the findings that living labs are a regional phenomenon and many national governments are quite disconnected from living labs and do not have well-developed policy frameworks relating to living labs, or indeed, arguably more broadly to support user or citizen participation.

In terms of user numbers, many living labs involve small numbers of users but the majority support over 1,000 users. Responses indicate that superficial interaction with end users is relatively easy to do while more involved or complex interactions are somewhat more difficult. A clear majority of living labs answered that the translation process from end users to products or service change was diffi- 
cult. It was interesting to note that some respondents found that the reason was a kind of 'lost in translation' effect, for example: "it can be hard to get constructive and instructive comments from users that are not used to giving feedback".

A majority of living labs would like access to support for evaluation and research training to assist with engaging with users and evaluating user involvement. Most living labs are inter-connected in some way with at least four other labs and communicated at least quarterly with the other labs with the main reason for this networking being to share experiences and knowledge.

The top challenges to living labs were given as funding; getting more partners and/or end users; and expanding activities and embedding user-centric activities in partners. The respondents indicated that funding their activities was a problem with most funding being project-based sourced primarily from nonprivate sector sources including public and academia. Most living labs simply didn't know how sustainable their lab would be over long time periods. This may reflect the relatively precarious position of living labs, that while many benefit from the European Commission's support for organisations to form partnerships through R\&D\&I funded activities, their position is not underpinned by national legislation, their governance is a partnership of differing and sometime competing interests and they are often regional actors with a regional remit and outlook with all that this entails.

What is remarkable about the findings is the diversity of purpose and scope of the living labs surveyed. We find living labs to be alive and healthy in 2011, somewhat uncertain about the future but enthusiastic about the challenges ahead to be tackled. It is apparent that many have a particular niche in which they operate. Some labs are region-based, others focus on a particular product family for example, automotive design, while others seek to address particular societal needs in, for example, healthcare. However, the use of technology to engage and support users as early as possible in product and service development is the common denominator for all of them.

Acknowledgements. The authors would like to thank Eileen Beamish, Social Research Centre Ltd and Donal McDade, Social Market Research Ltd for their support in the design of the survey. We would also like to thank the UK Higher Education Innovation Fund (HEIF) for its support to TRAIL, and to ENoLL for helping to promote the survey and its findings.

\section{References}

Mitchell, William J. (2003) Me++ : the cyborg self and the networked city, MIT Press, Cambridge, Mass.

Mulvenna, M.D., Martin, S., McDade, D., Beamish, E., de Oliveira, A., Kivilehto, A., (2011) TRAIL Living Labs Survey 2011: A survey of the ENOLL living labs, University of Ulster, 40 pages, ISBN-978-1-85923-249-1. 